\title{
Cadaverine's Functional Role in Plant Development and Environmental Response
}

\author{
Amy L. Jancewicz ${ }^{1 \dagger}$, Nicole M. Gibbs ${ }^{2 \dagger}$ and Patrick H. Masson ${ }^{1,2 *}$ \\ ${ }_{1}^{1}$ Program in Cellular and Molecular Biology, Laboratory of Genetics, University of Wisconsin-Madison, Madison, WI, USA, \\ ${ }^{2}$ Program in Plant Breeding and Plant Genetics, Laboratory of Genetics, University of Wisconsin-Madison, Madison, WI, \\ USA
}

OPEN ACCESS

Edited by:

Michael Wisniewski,

United States Department of Agriculture - Agricultural Research

Service, USA

Reviewed by:

Rajeev Arora,

lowa State University, USA

Lawrence V. Gusta,

University of Saskatchewan, Canada

Jia Liu,

Hefei University of Technology, China

*Correspondence:

Patrick H. Masson

phmasson@wisc.edu

tThese authors have contributed equally to this work.

Specialty section: This article was submitted to Plant Physiology,

a section of the journal Frontiers in Plant Science

Received: 04 April 2016 Accepted: 02 June 2016 Published: 21 June 2016

Citation: Jancewicz AL, Gibbs NM and Masson PH (2016) Cadaverine's Functional Role in Plant Development and Environmental Response.

Front. Plant Sci. 7:870 doi: 10.3389/fpls.2016.00870
Cadaverine derives from lysine in a pathway that is distinct from that of the other well-characterized ornithine- or arginine-derived polyamines. Despite a multitude of studies in bacterial systems, cadaverine has garnered little attention in plant research. Nonetheless, many plants have been found to synthesize it. For instance, the Leguminosae have been shown to produce cadaverine and use it as a precursor in the biosynthesis of quinolizidine alkaloids, secondary metabolites that are involved in insect defense and also display therapeutic pharmacological properties. Cadaverine is also present in the environment; it can be produced by rhizosphere and phyllosphere microbes. Markedly, exogenous cadaverine application causes alterations in rootsystem architecture. Previous research suggests cadaverine has a role in stress response, with groups reporting an increase in content upon exposure to heat, drought, salt, and oxidative stress. However, data regarding the role of cadaverine in stress response remains conflicted, as some plant systems show enhanced tolerance to stresses in its presence, while others show increased sensitivity to the same stresses. In this review, we summarize recent findings on the role of cadaverine in plant growth, development, and stress response. We also address the possible roles rhizosphere and phyllosphere microbes may play in the delivery of exogenous cadaverine near plant organs, and discuss our current understanding of the molecular pathways that contribute to cadaverine homeostasis and response in plants.

Keywords: polyamine, cadaverine, metabolism, plant development, root architecture, stress response, rhizosphere, phyllosphere

\section{INTRODUCTION}

Initially identified as a lysine decomposition product in organic matter, cadaverine, or 1,5pentanediamine, is found ubiquitously in the environment. Cadaverine, from the word, cadaver, is often associated with decaying matter and is one of the components that gives carrion its distinctive smell. Cadaverine functions in a multitude of cellular processes critical to living organisms. 
In Escherichia coli, cadaverine is used to mediate acid stress (Haneburger et al., 2012), and the deathly odor of cadaverine provides behavioral cues to animals (Rolen et al., 2003; Hussain et al., 2013). In plants, it has been reported to contribute to plant growth and development, cell signaling, stress response, and insect defense. The regulation of these diverse processes is critical for plant fitness in natural ecosystems, and also for healthy crop production.

This minireview highlights contributions to the understanding of cadaverine's functional role in plant development and environmental response by focusing on cadaverine's biosynthesis and metabolism, its impact on plant growth and development, its potential contribution to plant-microbe interactions, and its role in stress response.

\section{CADAVERINE BIOSYNTHESIS AND CONJUGATION}

Cadaverine is at the nexus of several biochemical pathways (Figure 1). Its main precursor is lysine, which is decarboxylated primarily by a lysine decarboxylase (LDC) found in the chloroplast (Schoofs et al., 1983; Wink, 1992; Bunsupa et al., 2012a). In some plants, such as Lathyrus sativus, cadaverine also appears to be synthesized from homoarginine via homoagmatine (reviewed in Bagni and Tassoni, 2001).

Endogenous cadaverine has been detected in several plant species, including wheat, rice, corn, and legumes (Felix and Harr, 1987), (reviewed in Tomar et al., 2013a). However, its concentration varies widely between species, organs, and even between different developmental stages of the same plant (Felix and Harr, 1987). In fact, some plants, such as Arabidopsis thaliana, may be deprived of a functional LDC, and have been reported to lack cadaverine. Moreover, enzymes previously annotated as putative LDCs in rice and Arabidopsis have instead been found to function in cytokinin biosynthesis (Kurakawa et al., 2007; Tokunaga et al., 2011).

A few dual-function enzymes, known as ornithine/lysine decarboxylases (O/LDCs), can accept both lysine and ornithine as substrates, thereby producing putrescine and cadaverine, respectively (Bunsupa et al., 2012a). In Leguminosae, the amount of cadaverine or putrescine synthesized by these enzymes appears to be regulated by substrate availability (Bunsupa et al., 2012a). O/LDCs are localized to the chloroplast, whereas the single-function ODC enzyme is localized to the cytosol, potentially allowing for compartmentalization of putrescine and cadaverine in plant cells (Voigt et al., 2000).

Most studies investigating cadaverine content in Arabidopsis thaliana have reported levels below detection (Bunsupa et al., 2012a; Liu et al., 2014; Strohm et al., 2015). Only one study has reported endogenous cadaverine ranging from 5 to $30 \mathrm{nmol} \mathrm{g}^{-1} \mathrm{FW}$ in this species (Shevyakova et al., 2001). The discrepancy between these studies may reflect differences in growth conditions, with differential effects on cadaverine metabolism and/or conjugation. Indeed, cadaverine concentration is frequently reported only for the free form. However, a large fraction of cadaverine appears to be either in a bound form (to cell wall, membranes, or nucleic acids), or conjugated to small molecules such as phenolics, and to proteins (reviewed in Bagni and Tassoni, 2001). For instance, in tobacco, $90 \%$ of the polyamine pool was found in the conjugated form (Torrigiani et al., 1987), and a hydroxycinnamoyl transferase enzyme was identified and purified, which conjugates cadaverine, along with putrescine and diaminopropane, to caffeoyl-, cinnamoyl-, feruloyl-, sinapoyl-, and p-coumaroyl-CoA acceptors (Negrel et al., 1992). Such conjugates are important because they contribute to wall-polymer crosslinking. Similarly, in lupin, free cadaverine was undetectable while conjugated cadaverine was reported to be $4-13 \mathrm{nMol} \mathrm{g}^{-1} \mathrm{FW}$ (Bunsupa et al., 2012a). Considering these observations, it will be important to test cadaverine levels in all polyamine pools to evaluate the possible existence of a cadaverine anabolic pathway in Arabidopsis.

Cadaverine is also a precursor for higher-order polyamines in plants. S-adenosyl methionine (SAM) is known to donate an $\mathrm{N}$-aminopropyl group to cadaverine to form 3-aminopropylcadaverine and $\mathrm{NN}^{\prime}$-bis(3aminopropyl) cadaverine (Igarashi et al., 1986). Little is known about the function of these derived molecules.

\section{CADAVERINE CATABOLISM AND CONVERSION TO ALKALOIDS}

The catabolism of cadaverine is facilitated by amine oxidases, which use oxygen, water, and cadaverine to form 5-aminopentanal, ammonia, and hydrogen peroxide (Cona et al., 2006; Bunsupa et al., 2012b). Hydrogen peroxide is a free radical that, among other functions, can serve as a stress signaling molecule, while ammonia acts as a nitrogen source and may modulate salt tolerance in some species (Cona et al., 2006; Bunsupa et al., 2012b; Meng et al., 2016).

In Leguminosae and several other plants, 5-aminopental serves as a critical substrate for the synthesis of secondary metabolites called quinolizidine alkaloids, which are involved in insect defense responses (Wink, 1992; Yokota Hirai et al., 2000; Cona et al., 2006; Bunsupa et al., 2012a,b). These alkaloids are produced in the chloroplast and protect the plants against herbivorous insects, either by acting as a deterrent to feeding, or resulting in toxicity for the insect by affecting protein biosynthesis, membrane stability, or DNA and RNA processes (Wink, 1992, 2010; Bunsupa et al., 2012a).

Interestingly, some quinolizidine alkaloids, like lobeline, have been used as pharmaceuticals to treat central nervous system disorders and addiction by regulating dopamine uptake and release, and acetylcholine receptor modulation (Dwoskin and Crooks, 2002; Bunsupa et al., 2012b; Kaniakova et al., 2014). Alzheimer's disease has also been treated using huperzine A, a quinolizodine-derived alkaloid that serves to increase acetylcholine levels by acting as a selective inhibitor of acetylcholinesterase (Bai et al., 2000; Bunsupa et al., 2012b). 


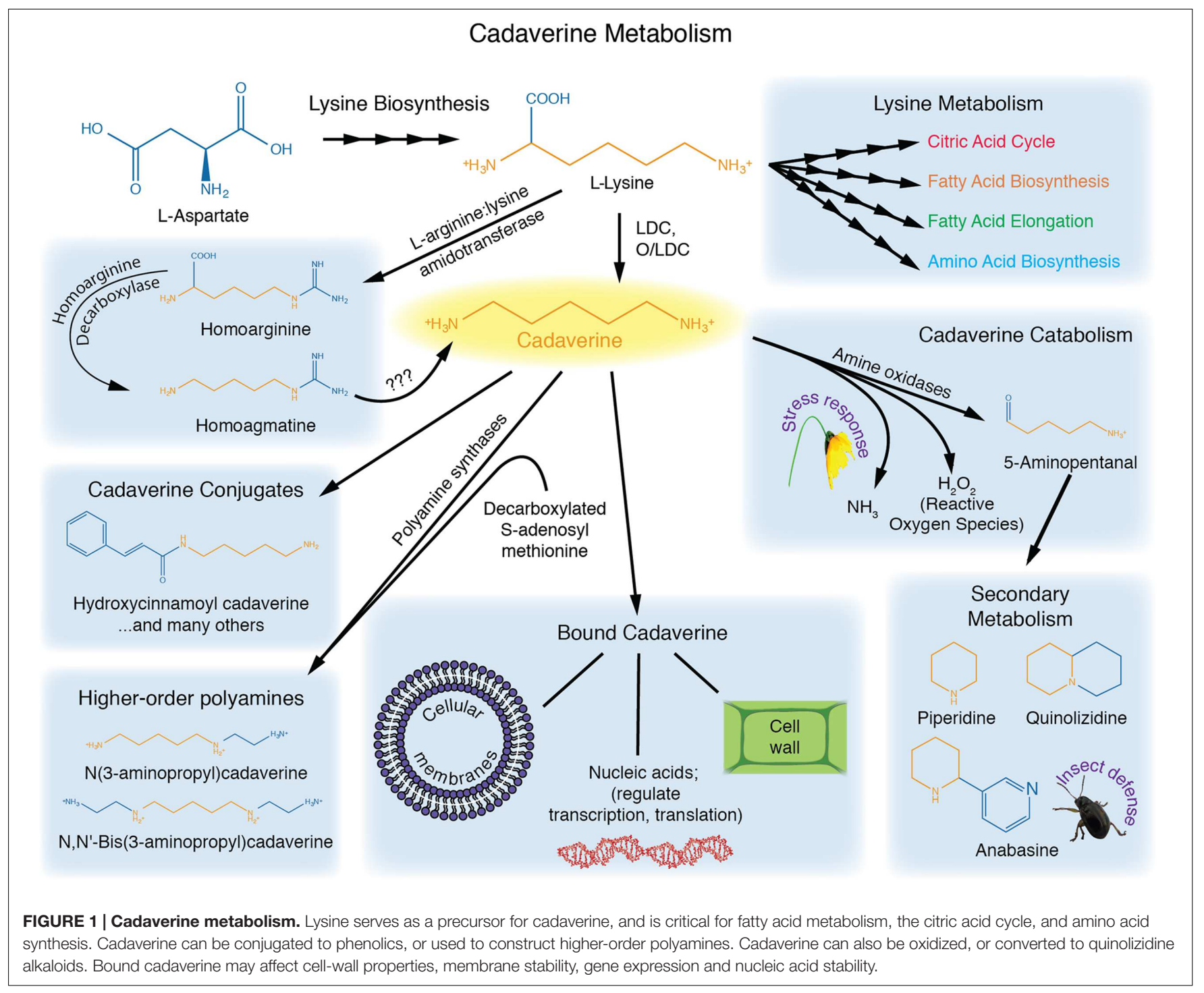

\section{IS ENVIRONMENTAL CADAVERINE TAKEN UP BY PLANTS?}

Regardless of whether a given plant engages in de novo cadaverine biosynthesis, it is possible for this plant to take up cadaverine from its environment and use it for downstream metabolism and signaling. Indeed, maize seedlings were reported to take up exogenous cadaverine, putrescine, and paraquat (PQ, a broad-spectrum herbicide with structural similarity to polyamines) with similar kinetic profiles, and competition assays suggested a common plasmalemma transporter for these molecules (Hart et al., 1992). Similarly, soybean and rice were shown to take up cadaverine (Cassán et al., 2009; Ohe et al., 2010).

Until recently, the well-characterized polyamine transporters in plants, including members of the L-Amino acid Transporter family (LAT proteins, also named Polyamine Uptake Transporters (PUTs)) and Organic Cation Transporters
(OCTs), had been primarily investigated for function in the transport of putrescine-derived polyamines or other organic cations (Mulangi et al., 2011; Fujita et al., 2012). OCT1, on the other hand, was suggested to function as a cadaverine efflux transporter because oct1 knockout plants are known to display increased sensitivity to cadaverine (Strohm et al., 2015), and because spermine synthase over-expressing plants respond to cadaverine by increasing OCT1 expression, possibly to eliminate excessive polyamine from the cells (Sagor et al., 2016).

These results are important because they suggest a contribution of two plasma membrane-associated proteins in cadaverine transport in plants. However, it will be critical to confirm these observations by verifying the cadaverine-transport activity of both proteins in heterologous expression systems. It will also be important to investigate other members of the AtLAT and OCT families for potential function in cadaverine transport. 


\section{DO MICROBES GENERATE ENVIRONMENTAL CADAVERINE FOR THE PLANT?}

In the laboratory, plants are often grown in sterile conditions, or with limited access to their normal complement of microbes. Yet, in nature, protozoa, fungi, algae, and bacteria associate very intimately with shoot or root tissues, forming the phyllosphere and rhizosphere, respectively. Many microbes also colonize the internal spaces within plant organs, forming the endosphere (reviewed in de Vrieze, 2015, and in Schlaeppi and Bulgarelli, 2015), (Kuiper et al., 2001; Cassán et al., 2009; Lavizzari et al., 2010; Lundberg et al., 2012; Di Martino et al., 2013; Lebeis et al., 2015). These intimate associations between microbes and plants allow bidirectional signal exchange between organisms. They form incredibly complex biological networks that contribute to plant fitness, productivity and environmental responses (Ozawa et al., 2009; Pangesti et al., 2013).

Several microbes in the phyllosphere have been shown to produce cadaverine, sometimes at high concentrations. One study in spinach leaves detected 240 different bacterial isolates capable of producing cadaverine (Lavizzari et al., 2010). The rhizosphere also contains microbes that provide cadaverine for the plant, with downstream effects on stress protection and biomass production. For instance, rice seedlings inoculated with the cadaverine-producing bacterium Azospirillum brasilense, accumulated cadaverine in their tissues (in the pM range) (Cassán et al., 2009). Interestingly, rice treated with either cadaverine alone, or with Azospirillum brasilense culture, displayed gains in fresh and dry weight, and decreased sensitivity to osmotic stress, relative to controls (Cassán et al., 2009). These findings suggest a role for rhizosphere symbiont-synthesized cadaverine in the regulation of plant growth and stress mitigation. However, to solidify these findings, it will be important to determine the level of cadaverine in untreated rice seedlings. It will also be important to verify the inability of cadaverine-defective Azospirillum mutants to modulate plant sensitivity to stress.

\section{CADAVERINE MODULATES PLANT DEVELOPMENT}

Alterations in cadaverine concentration within a plant, either caused by environmental stimulation of synthesis or through exposure to exogenous cadaverine, have been shown to induce morphological changes in a wide array of species, including Arabidopsis, rice, soybean, and Scots pine (Gamarnik and Frydman, 1991; Niemi et al., 2002; Cassán et al., 2009; Campestre et al., 2011; Liu et al., 2014; Strohm et al., 2015). Table 1 summarizes reports of developmental responses to exogenous cadaverine.

Early functional studies were carried out in soybean seedlings, a species that produces relatively high amounts of cadaverine. In this system, exogenous cadaverine caused a decrease in primary root growth and an increase in lateral root branching (Gamarnik and Frydman, 1991). Similar observations were made in Arabidopsis thaliana, where alterations in primary root growth stemmed from a decrease in both cell division and cell elongation (Strohm et al., 2015).

Recently, it was suggested that cadaverine regulates root development and stress response by inducing spermine accumulation (Liu et al., 2014). In this study, spms and pao4-1 mutants were found to display resistant and hypersensitive root-growth responses to cadaverine, respectively, compared to wild type. Cadaverine treatment promoted putrescine and spermine accumulation while reducing spermidine content. On the other hand, spermine was also shown to modulate plant's sensitivity to cadaverine, as discussed earlier in this review (Sagor et al., 2016). Taken together, these initial studies are exciting because they begin to explore possible crosstalk between the cadaverine and putrescine-derived pathways in the modulation of root growth.

Reactive oxygen species (ROS) may also contribute to rootgrowth responses to cadaverine. Indeed, ROS were previously shown to play important roles in root development and stress response (Neill et al., 2002). As discussed earlier, cadaverine breakdown by amine oxidases primarily associated with the root apoplast leads to the production of hydrogen peroxide (Gamarnik and Frydman, 1991; Torrigiani and Scoccianti, 1995; PlanasPortell et al., 2013), a signaling molecule known to function at multiple levels in plant cells, including regulation of gene expression, DNA repair, cell-wall cross-linking, and programmed cell death (reviewed in Neill et al., 2002). Importantly, treating plants with hydrogen peroxide leads to primary root growth inhibition (Dunand et al., 2007). Analysis of ROS generation after spermidine treatment in Arabidopsis revealed a specific ratio of hydrogen peroxide to superoxide dictated the root growth phenotype characteristic of spermidine response (Andronis et al., 2014). By analogy, cadaverine may be partially acting through ROS to induce phenotypic changes, although more work is needed to test this contention.

Loci that contribute to root-growth response to cadaverine can be identified through exploration of the natural variation existing between plant accessions. In one study, ten Arabidopsis accessions were tested on cadaverine-containing media, showing accessionspecific cadaverine responses for primary root growth, skewing, waving, and lateral root number (Strohm et al., 2015). Using a Quantitative Trait Loci (QTL) approach, the authors identified ORGANIC CATION TRANSPORTER 1 (OCT1) as contributing to the variation between the Ler and Cvi accessions (Strohm et al., 2015). OCT1 encodes a membrane-associated protein that was previously implicated in carnitine transport (Vaz and Wanders, 2002; Lelandais-Brière et al., 2007). Null oct1 mutants were shown to exhibit a hypersensitive root-growth response to cadaverine (Strohm et al., 2015), suggesting a role for OCT1 in cadaverine efflux (Sagor et al., 2016; see above). This important result suggests that the natural variation existing between plant populations can be explored for identification of genes involved in the cadaverine-response pathway.

The inducing effects of cadaverine on root branching are equally interesting. Lateral root development is a complex, auxin-dependent process that has been shown to involve multiple phases, from initiation at the pericycle and primordium 
TABLE 1 | Exogenous application of cadaverine induces morphological changes.

\begin{tabular}{|c|c|c|c|c|}
\hline Species & Treatment conditions & Result of cad treatment & [Cad] & Percent change \\
\hline Arabidopsis thaliana ${ }^{1}$ & $\begin{array}{l}\text { Germinated and grown on Cad } \\
\text { for } 2 \text { weeks }\end{array}$ & Primary root growth inhibition & $2 \mathrm{mM}$ & Not quantified \\
\hline \multirow[t]{8}{*}{ Arabidopsis thaliana $^{2}$} & \multirow{8}{*}{$\begin{array}{l}\text { Germinated and grown on Cad } \\
\text { for } 6 \text { days }\end{array}$} & \multirow[t]{2}{*}{ Primary root growth inhibition } & $100 \mu \mu \mathrm{M}$ & $2-65 \% * A$ \\
\hline & & & $500 \mu \mathrm{M}$ & $25-70 \% * A$ \\
\hline & & \multirow[t]{2}{*}{ Change in lateral root branching } & $100 \mu \mathrm{M}$ & $-20-630 \% * A$ \\
\hline & & & $500 \mu \mathrm{M}$ & $5-850 \% * A$ \\
\hline & & \multirow{2}{*}{$\begin{array}{l}\text { Change in horizontal growth } \\
\text { index }\end{array}$} & $100 \mu \mathrm{M}$ & $10-70 \% * A$ \\
\hline & & & $500 \mu \mathrm{M}$ & $30-70 \% * A$ \\
\hline & & \multirow[t]{2}{*}{ Change in straightness } & $100 \mu \mathrm{M}$ & $-2-10 \% * A$ \\
\hline & & & $500 \mu \mathrm{M}$ & $-10-20 \% * A$ \\
\hline \multirow[t]{2}{*}{ Brassica juncea ${ }^{3}$} & $\begin{array}{l}\text { Sown on filter paper with Cad } \\
\text { solution }\end{array}$ & $\begin{array}{l}\text { Increased germination after } \\
24 \mathrm{~h}\end{array}$ & $1 \mathrm{mM}$ & $5 \% *$ \\
\hline & $\begin{array}{l}\text { Watered with Cad solution for } \\
7 \text { days }\end{array}$ & Decreased fresh weight & $1 \mathrm{mM}$ & $15 \% *$ \\
\hline Glycine max ${ }^{4}$ & $\begin{array}{l}\text { Germinated and grown on Cad } \\
\text { for } 5 \text { days }\end{array}$ & $\begin{array}{l}\text { Enhanced lateral root } \\
\text { development }\end{array}$ & $1 \mathrm{mM}$ & Not quantified \\
\hline \multirow[t]{3}{*}{ Glycine $\max ^{5}$} & \multirow{3}{*}{$\begin{array}{l}\text { Germinated on soil and } \\
\text { watered with Cad for } 7 \text { days }\end{array}$} & \multirow[t]{3}{*}{ Hypocotyl elongation } & $25 \mu \mathrm{M}$ & $30 \% *$ \\
\hline & & & $50 \mu \mathrm{M}$ & $40 \% *$ \\
\hline & & & $100 \mu \mathrm{M}$ & $20 \% *$ \\
\hline \multirow[t]{8}{*}{ Hordeum vulgare 6} & \multirow{3}{*}{$\begin{array}{l}\text { Germinated and grown on Cad } \\
\text { for } 7 \text { days }\end{array}$} & Increased coleoptile length & $10 \mu \mathrm{M}$ & $21 \%$ \\
\hline & & Increased fresh weight & $10 \mu \mathrm{M}$ & $4 \%$ \\
\hline & & Increased radicle number & $10 \mu \mathrm{M}$ & $25 \%$ \\
\hline & \multirow[t]{5}{*}{$\begin{array}{l}\text { Cad pretreatment for } 7 \text { days } \\
\text { then moved to soil until day } 20\end{array}$} & $\begin{array}{l}\text { Increase in adaxial epidermis } \\
\text { cells number }\end{array}$ & $10 \mu \mathrm{M}$ & $34 \%$ \\
\hline & & $\begin{array}{l}\text { Increase in abaxial epidermis } \\
\text { cells number }\end{array}$ & $10 \mu \mathrm{M}$ & $27 \%$ \\
\hline & & $\begin{array}{l}\text { Increased distance between } \\
\text { vascular bundles }\end{array}$ & $10 \mu \mathrm{M}$ & $10 \%$ \\
\hline & & Increase in stomatal length & $10 \mu \mathrm{M}$ & $27 \%$ \\
\hline & & $\begin{array}{l}\text { Increased stomatal width of the } \\
\text { abaxial leaf }\end{array}$ & $10 \mu \mathrm{M}$ & $3 \%$ \\
\hline \multirow[t]{8}{*}{ Oryza sativa ${ }^{7}$} & \multirow[t]{8}{*}{$\begin{array}{l}\text { Cad applied on leaf surface of } \\
2 \text { day-old seedlings and grown } \\
\text { for } 7 \text { days after treatment }\end{array}$} & \multirow[t]{2}{*}{ Increased root fresh weight } & $1 \mathrm{nM}$ & $33 \% * \mathrm{~B}$ \\
\hline & & & $1 \mu \mathrm{M}$ & $44 \% * B$ \\
\hline & & \multirow[t]{2}{*}{ Increased shoot fresh weight } & $1 \mathrm{nM}$ & $24 \% * B$ \\
\hline & & & $1 \mu \mathrm{M}$ & $22 \% * B$ \\
\hline & & \multirow[t]{2}{*}{ Increased root dry weight } & $1 \mathrm{nM}$ & $29 \% * B$ \\
\hline & & & $1 \mu \mathrm{M}$ & $30 \% * B$ \\
\hline & & \multirow[t]{2}{*}{ Increased shoot dry weight } & $1 \mathrm{nM}$ & $14 \% * B$ \\
\hline & & & $1 \mu \mathrm{M}$ & $22 \% * B$ \\
\hline Pinus sylvestris ${ }^{8}$ & $\begin{array}{l}\text { Hypocotyl cuttings from } 17 \text { day } \\
\text { old seedlings cultured } 4 \text { weeks } \\
\text { in Cad }\end{array}$ & Decrease in root formation & $500 \mu \mathrm{M}$ & $10 \% * C$ \\
\hline \multirow[t]{2}{*}{ Vicia faba 9} & \multirow{2}{*}{$\begin{array}{l}\text { Guard cell protoplasts from } \\
3 \text { week old plants treated with } \\
\text { Cad }\end{array}$} & Inhibition of potassium influx & $1 \mathrm{mM}$ & $37 \% *$ \\
\hline & & Decrease in stomatal pore size & $1 \mathrm{mM}$ & $71 \% *$ \\
\hline
\end{tabular}

Summary of morphological changes induced by exogenous cadaverine treatment. Effect of cadaverine treatment was standardized to percentage for all studies. * Indicates approximate value when raw data was unavailable. (A) Results are presented as a range of values; the effect of cadaverine is dependent on natural accession studied. (B) No statistical test of significance. (C) Incomplete statistics. References: (1) Liu et al., 2014; (2) Strohm et al., 2015; (3) Tomar et al., 2013b; (4) Gamarnik and Frydman, 1991; (5) Campestre et al., 2011; (6) Çavuşoğlu et al., 2007; (7) Cassán et al., 2009; (8) Niemi et al., 2002; (9) Liu et al., 2000.

development to emergence from the primary root and subsequent growth (reviewed in Lavenus et al., 2013). Effort is needed to determine how cadaverine affects lateral root formation, the phases of lateral root development it acts upon, and to establish possible connections between cadaverine and hormone signaling.
In addition to modulating root-system architecture, cadaverine has also been shown to affect several aspects of shoot development, including promoting hypocotyl elongation in soybean (Campestre et al., 2011) and altering the number of epidermal cells and stomata morphology in leaves of barley (Çavuşoǧlu et al., 2007). Cadaverine has also been tied to 
plant reproduction; its content spiked in Polianthes tuberosa corms during floral initiation and then declined before floral development, suggesting a role in floral initiation (Huang et al., 2004).

\section{CADAVERINE MAY CONTRIBUTE TO ENVIRONMENTAL STRESS RESPONSE}

As with other polyamines, cadaverine has been implicated in stress response. However, there is a dichotomy between cadaverine acting as a stress protectant or exacerbating stress damage.

Cadaverine has been reported to facilitate seed germination and seedling growth under environmental stress. For instance, mustard seeds (Brassica juncea L.) exposed to salt, lead or cadmium displayed increased germination rate when treated with cadaverine, suggesting a role for this diamine in stress mitigation (Tomar et al., 2013b). Similarly, in barley (Hordeum vulgare L.), exogenous cadaverine promoted seed germination and seedling growth in the presence of salt (Çavuşoğlu et al., 2007).

Cadaverine was reported to accumulate in the tissues of several plant species in response to a wide variety of environmental stimuli (Aziz et al., 1998; Kuznetsov et al., 2007; Cassán et al., 2009; Sziderics et al., 2010; SimonSarkadi et al., 2014). For instance, in the common ice plant (Mesembryanthemum crystallinum L.), cadaverine accumulated in response to heat shock, salt stress, and exogenous ethylene treatment (Shevyakova et al., 2001; Kuznetsov et al., 2007). Furthermore, local application of heat shock to either shoots or roots promoted cadaverine accretion in distal organs, suggesting transport throughout the plant (Shevyakova et al., 2001).

Similarly, pepper plants (Capsicum annuum L.) were shown to accumulate cadaverine and putrescine in leaves, and spermidine and spermine in roots, upon exposure to drought conditions (Sziderics et al., 2010). In leaves, polyamines may contribute some protective effect against water-deficient conditions by inhibiting potassium influx into guard cells, thereby inducing stomatal closure and reducing water loss (Liu et al., 2000).

While the previous studies reported cadaverine-induced stress mitigation, an experiment with Arabidopsis thaliana suggested induction of stress hypersensitivity. In this experiment, seedlings were pretreated with cadaverine for 1 week, and then moved to media containing $150 \mathrm{mM} \mathrm{NaCl}$ for another week. Cadaverinepretreated seedlings displayed a hypersensitive response to salt despite an obvious accumulation of spermine, a polyamine previously associated with salt-stress mitigation (Yamaguchi et al., 2006; Liu et al., 2014). This result was interpreted to suggest that increased spermine levels, per se, may not be sufficient for salt-stress mitigation. Instead, an increase in spermine catabolic products may be required (Liu et al., 2014).

The previous discussion nicely illustrates a major complication in the study of cadaverine's role in plant stress response: many environmental stimuli, such as cold, salt, and drought stresses, also influence the expression of putrescine-derived polyamine biosynthetic enzymes (reviewed in Alcázar et al., 2010). Furthermore, cadaverine is also known to influence the accumulation of putrescine-derived polyamines in plant tissues (Liu et al., 2014). Therefore, the contribution of cadaverine to plant stress response cannot be assessed in isolation. Instead, it will be important to carefully examine its impact in relation to that of putrescine-derived polyamines under the same conditions. Identification and characterization of additional polyamine response mutants will undoubtedly help in this difficult endeavor.

To further assess cadaverine's role in plant-stress response, it will be critical to elucidate the pathways that lead to its biosynthesis, conjugation, transport and catabolism in control and stressful conditions. In species lacking clear LDC genes, such as Arabidopsis and rice, it will be necessary to investigate possible alternative pathway(s) for stress-induced cadaverine synthesis or uptake. In this regard, cadaverine delivery by rhizosphere and phyllosphere microbes should be considered. A more global analysis of the types of cadaverine-producing microbes associated with various plant species would be useful, as would an evaluation of the amount of cadaverine they deliver to the plant under diverse conditions. Furthermore, characterization of plant stress-response in the presence of cadaverine-defective microbial mutants should help demonstrate a role for microbial-derived cadaverine in stress mitigation.

\section{CONCLUSION AND FUTURE PROSPECTS}

Through endogenous synthesis or environmental uptake, cadaverine induces morphological changes that modulate plant development and environmental stress responses. This minireview is meant to provide a concise summary of the current knowledge of cadaverine's role in plants, and is not an exhaustive review of relevant literature in the field.

While the molecular mechanisms of cadaverine action remain elusive, current literature has highlighted how it is produced, taken up, and metabolized in a few plant species. Research has also documented a role for cadaverine in plant growth, development and stress response. These data offer new avenues for increasing crop yield and engineering stress-tolerant plants.

Unfortunately, large gaps remain in our understanding of plant responses to cadaverine. To date, only a few genes contributing to cadaverine metabolism or response have been characterized. Additional gene identification and functional characterization will be critical to better understand cadaverine function in plants. In this context, recent technological developments in genetics, systems biology and genome editing offer amazing opportunities to unravel cadaverine-response pathways and related gene interaction networks.

Ultimately, expanding beyond current experimental setups that mostly investigate plant monocultures to also incorporate cadaverine-producing microbes, will be critical to evaluate the contribution of cadaverine in bidirectional plant-microbe interactions and their potential roles in environmental perception and stress responses. 
Finally, human health will also benefit from a deeper understanding of these pathways, beyond its effects on crop improvement for food, feed and fiber production. Indeed, quinolizidine alkaloids are already used as pharmaceuticals to treat central nervous system disorders, addiction, and Alzheimer's disease, and could serve as excellent starting points in the design of additional compounds for use in the treatment of multiple ailments.

\section{AUTHOR CONTRIBUTIONS}

AJ and NG contributed equally to this work. They wrote sections of the manuscript, then contributed to its editing and final

\section{REFERENCES}

Alcázar, R., Altabella, T., Marco, F., Bortolotti, C., Reymond, M., Koncz, C., et al. (2010). Polyamines: molecules with regulatory functions in plant abiotic stress tolerance. Planta 231, 1237-1249. doi: 10.1007/s00425-010-1130-0

Andronis, E. A., Moschou, P. N., Toumi, I., and Roubelakis-Angelakis, K. A. (2014). Peroxisomal polyamine oxidase and NADPH-oxidase cross-talk for ROS homeostasis which affects respiration rate in Arabidopsis thaliana. Front. Plant Sci. 5:132. doi: 10.3389/fpls.2014.00132

Aziz, A., Martin-Tanguy, J., and Larher, F. (1998). Stress-induced changes in polyamine and tyramine levels can regulate proline accumulation in tomato leaf discs treated with sodium chloride. Physiol. Plant. 104, 195-202. doi: 10.1034/j.1399-3054.1998.1040207.x

Bagni, N., and Tassoni, A. (2001). Biosynthesis, oxidation and conjugation of aliphatic polyamines in higher plants. Amino Acids 20, 301-317. doi: $10.1007 / \mathrm{s} 007260170046$

Bai, D. L., Tang, X. C., and He, X. C. (2000). Huperzine A, a potential therapeutic agent for treatment of Alzheimer's disease. Curr. Med. Chem. 7, 355-374. doi: 10.2174/0929867003375281

Bunsupa, S., Katayama, K., Ikeura, E., Oikawa, A., Toyooka, K., Saito, K., et al. (2012a). Lysine decarboxylase catalyzes the first step of quinolizidine alkaloid biosynthesis and coevolved with alkaloid production in leguminosae. Plant Cell 24, 1202-1216. doi: 10.1105/tpc.112.095885

Bunsupa, S., Yamazaki, M., and Saito, K. (2012b). Quinolizidine alkaloid biosynthesis: recent advances and future prospects. Front. Plant Sci. 3:239. doi: $10.3389 /$ fpls.2012.00239

Campestre, M. P., Bordenave, C. D., Origone, A. C., Menéndez, A. B., Ruiz, O. A., Rodríguez, A. A., et al. (2011). Polyamine catabolism is involved in response to salt stress in soybean hypocotyls. J. Plant Physiol. 168, 1234-1240. doi: 10.1016/j.jplph.2011.01.007

Cassán, F., Maiale, S., Masciarelli, O., Vidal, A., Luna, V., and Ruiz, O. (2009). Cadaverine production by Azospirillum brasilense and its possible role in plant growth promotion and osmotic stress mitigation. Eur. J. Soil Biol. 45, 12-19. doi: 10.1016/j.ejsobi.2008.08.003

Çavuşoğlu, K., Kıl lıç, S., and Kabar, K. (2007). Some morphological and anatomical observations during alleviation of salinity $(\mathrm{NaCI})$ stress on seed germination and seedling growth of barley by polyamines. Acta Physiol. Plant 29, 551-557. doi: 10.1007/s11738-007-0066-x

Cona, A., Rea, G., Angelini, R., Federico, R., and Tavladoraki, P. (2006). Functions of amine oxidases in plant development and defence. Trends Plant Sci. 11, 80-88. doi: 10.1016/j.tplants.2005.12.009

de Vrieze, J. (2015). The littlest farmhands. Science 349, 680-683. doi: $10.1126 /$ science.349.6249.680

Di Martino, M. L., Campilongo, R., Casalino, M., Micheli, G., Colonna, B., and Prosseda, G. (2013). Polyamines: emerging players in bacteria-host interactions. Int. J. Med. Microbiol. 303, 484-491. doi: 10.1016/j.ijmm.2013.06.008

Dunand, C., Crèvecoeur, M., and Penel, C. (2007). Distribution of superoxide and hydrogen peroxide in Arabidopsis root and their influence on root development: possible interaction with peroxidases. New Phytol. 174, 332-341. doi: 10.1111/j.1469-8137.2007.01995.x formatting. AJ contributed Figure 1; NG contributed Table 1. PM contributed to editing materials written by $\mathrm{AJ}$ and NG, and final integration of the various sections.

\section{FUNDING}

This mini review was made possible by a HATCH grant (\#WIS10338), a Bridge award from the College of Agriculture and Life Sciences, and by a Fall Competition Award from the Office of the Vice Chancellor for Research and Graduate Education from the University of Wisconsin-Madison, to PM. AJ was supported by a MBTG Training Grant and by an AOF award.

Dwoskin, L. P., and Crooks, P. A. (2002). A novel mechanism of action and potential use for lobeline as a treatment for psychostimulant abuse. Biochem. Pharmacol. 63, 89-98. doi: 10.1016/S0006-2952(01)00899-1

Felix, H., and Harr, J. (1987). Association of polyamines to different parts of various plant species. Physiol. Plant. 71, 245-250. doi: 10.1111/j.13993054.1987.tb04337.x

Fujita, M., Fujita, Y., Iuchi, S., Yamada, K., Kobayashi, Y., Urano, K., et al. (2012). Natural variation in a polyamine transporter determines paraquat tolerance in Arabidopsis. Proc. Natl. Acad. Sci. U.S.A. 109, 6343-6347. doi: 10.1073/pnas.1121406109

Gamarnik, A. A., and Frydman, R. B. R. (1991). Cadaverine, an essential diamine for the normal root development of germinating soybean (Glycine max) seeds. Annu. Rev. Plant Physiol. 97, 778-785. doi: 10.1104/pp.97. 2.778

Haneburger, I., Fritz, G., Jurkschat, N., Tetsch, L., Eichinger, A., Skerra, A., et al. (2012). Deactivation of the E. coli $\mathrm{pH}$ stress sensor CadC by cadaverine. J. Mol. Biol. 424, 15-27. doi: 10.1016/j.jmb.2012.08.023

Hart, J. J., Ditomaso, J. M., Linscott, D. L., and Kochian, L. V. (1992). Transport interactions between paraquat and polyamines in roots of intact maize seedlings. Plant Physiol. 99, 1400-1405. doi: 10.1104/pp.99.4.1400

Huang, C.-K., Chang, B.-S., Wang, K.-C., Her, S.-J., Chen, T.-W., Chen, Y.-A., et al. (2004). Changes in polyamine pattern are involved in floral initiation and development in Polianthes tuberosa. J. Plant Physiol. 161, 709-713. doi: 10.1078/0176-1617-01256

Hussain, A., Saraiva, L. R., Ferrero, D. M., Ahuja, G., Krishna, V. S., Liberles, S. D., et al. (2013). High-affinity olfactory receptor for the death-associated odor cadaverine. Proc. Natl. Acad. Sci. U.S.A. 110, 19579-19584. doi: $10.1073 /$ pnas. 1318596110

Igarashi, K., Hamasaki, H., Miura, A., Kakegawa, T., Hirose, S., Matsuzaki, S., et al. (1986). Formation of a compensatory polyamine by Escherichia coli polyaminerequiring mutants during growth in the absence of polyamines. J. Bacteriol. 166, 128-134.

Kaniakova, M., Skrenkova, K., Adamek, S., Vyskocil, F., and Krusek, J. (2014). Different effects of lobeline on neuronal and muscle nicotinic receptors. Eur. J. Pharmacol. 738, 352-359. doi: 10.1016/j.ejphar.2014.05.057

Kuiper, I., Bloemberg, G. V., and Noreen, S. (2001). Increased uptake of putrescine in the rhizosphere inhibits competitive root colonization by Pseudomonas fluorescens strain WCS365. Mol. Plant 14, 1096-1104. doi: 10.1094/MPMI.2001.14.9.1096

Kurakawa, T., Ueda, N., Maekawa, M., Kobayashi, K., Kojima, M., Nagato, Y., et al. (2007). Direct control of shoot meristem activity by a cytokinin-activating enzyme. Nature 445, 652-655. doi: 10.1038/nature05504

Kuznetsov, V., Shorina, M., Aronova, E., Stetsenko, L., Rakitin, V., and Shevyakova, N. (2007). NaCl- and ethylene-dependent cadaverine accumulation and its possible protective role in the adaptation of the common ice plant to salt stress. Plant Sci. 172, 363-370. doi: 10.1016/j.plantsci.2006.09.012

Lavenus, J., Goh, T., Roberts, I., Guyomarc'h, S., Lucas, M., De Smet, I., et al. (2013). Lateral root development in Arabidopsis: fifty shades of auxin. Trends Plant Sci. 18, 450-458. doi: 10.1016/j.tplants.2013.04.006 
Lavizzari, T., Breccia, M., Bover-Cid, S., Vidal-Carou, M. C., and Veciana-Nogués, M. T. (2010). Histamine, cadaverine, and putrescine produced in vitro by enterobacteriaceae and pseudomonadaceae isolated from spinach. J. Food Prot. 73, 385-389. doi: 10.1007/s00217-006-0530-7

Lebeis, S. L., Paredes, S. H., Lundberg, D. S., Breakfield, N., Gehring, J., McDonald, M., et al. (2015). Salicylic acid modulates colonization of the root microbiome by specific bacterial taxa. Science 349, 860-864. doi: $10.1126 /$ science.aaa8764

Lelandais-Brière, C., Jovanovic, M., Torres, G. A. M., Perrin, Y., Lemoine, R. Corre-Menguy, F., et al. (2007). Disruption of AtOCT1, an organic cation transporter gene, affects root development and carnitine-related responses in Arabidopsis. Plant J. 51, 154-164. doi: 10.1111/j.1365-313X.2007.03131.x

Liu, K., Fu, H., Bei, Q., and Luan, S. (2000). Inward potassium channel in guard cells as a target for polyamine regulation of stomatal movements. Annu. Rev. Plant Physiol. 124, 1315-1326. doi: 10.1104/pp.124.3.1315

Liu, T., Dobashi, H., Kim, D. W., Sagor, G. H. M., Niitsu, M., Berberich, T., et al. (2014). Arabidopsis mutant plants with diverse defects in polyamine metabolism show unequal sensitivity to exogenous cadaverine probably based on their spermine content. Physiol. Mol. Biol. Plants 20, 151-159. doi: 10.1007/s12298014-0227-5

Lundberg, D. S., Lebeis, S. L., Paredes, S. H., Yourstone, S., Gehring, J., Malfatti, S., et al. (2012). Defining the core Arabidopsis thaliana root microbiome. Nature 488, 86-90. doi: 10.1038/nature11237

Meng, S., Su, L., Li, Y., Wang, Y., Zhang, C., and Zhao, Z. (2016). Nitrate and ammonium contribute to the distinct nitrogen metabolism of Populus simonii during moderate salt stress. PLoS ONE 11:e0150354. doi: 10.1371/journal.pone.0150354

Mulangi, V., Phuntumart, V., Aouida, M., Ramotar, D., and Morris, P. (2011). Functional analysis of OsPUT1, a rice polyamine uptake transporter. Planta 235, 1-11. doi: 10.1007/s00425-011-1486-9

Negrel, J., Paynot, M., and Javelle, F. (1992). Purification and properties of putrescine hydroxycinnamoyl transferase from tobacco (Nicotiana tabacum) cell suspensions. Plant Physiol. 98, 1264-1269. doi: 10.1104/pp.98. 4.1264

Neill, S. J., Desikan, R., Clarke, A., Hurst, R. D., and Hancock, J. T. (2002). Hydrogen peroxide and nitric oxide as signalling molecules in plants. J. Exp. Bot. 53, 1237-1247. doi: 10.1093/jexbot/53.372.1237

Niemi, K., Häggman, H., and Sarjala, T. (2002). Effects of exogenous diamines on the interaction between ectomycorrhizal fungi and adventitious root formation in Scots pine in vitro. Tree Physiol. 22, 373-381. doi: 10.1093/treephys/22.6.373

Ohe, M., Sasaki, H., Niitsu, M., Bagni, N., Tassoni, A., and Matsuzaki, S. (2010). Cadaverine turnover in soybean seedlings using $15 \mathrm{~N}$-labelled lysine and cadaverine. Plant Physiol. Biochem. 48, 591-595. doi: 10.1016/j.plaphy.2010.01.018

Ozawa, R., Bertea, C. M., Foti, M., Narayana, R., Arimura, G. I., Muroi, A., et al. (2009). Exogenous polyamines elicit herbivore-induced volatiles in Lima bean leaves: involvement of calcium. $\mathrm{H} 2 \mathrm{O} 2$ and jasmonic acid. Plant Cell Physiol. 50, 2183-2199. doi: 10.1093/pcp/pcp153

Pangesti, N., Pineda, A., Pieterse, C. M. J., Dicke, M., and van Loon, J. J. A. (2013). Two-way plant-mediated interactions between root-associated microbes and insects: from ecology to mechanisms. Front. Plant Sci. 4:414. doi: $10.3389 /$ fpls.2013.00414

Planas-Portell, J., Gallart, M., Tiburcio, A. F., and Altabella, T. (2013). Coppercontaining amine oxidases contribute to terminal polyamine oxidation in peroxisomes and apoplast of Arabidopsis thaliana. BMC Plant Biol. 13:109. doi: 10.1186/1471-2229-13-109

Rolen, S. H., Sorensen, P. W., Mattson, D., and Caprio, J. (2003). Polyamines as olfactory stimuli in the goldfish Carassius auratus. J. Exp. Biol. 206, 1683-1696. doi: $10.1242 /$ jeb.00338

Sagor, G. H. M., Berberich, T., Kojima, S., Niitsu, M., and Kusano, T. (2016). Spermine modulates the expression of two probable polyamine transporter genes and determines growth responses to cadaverine in Arabidopsis. Plant Cell Rep. 35, 1247-1257. doi: 10.1007/s00299-016-1957-3

Schlaeppi, K., and Bulgarelli, D. (2015). The plant microbiome at work. Mol. Plant Microbe Interact. 28, 212-217. doi: 10.1094/MPMI-10-14-0334-FI

Schoofs, G., Teichmann, S., Hartmann, T., and Wink, M. (1983). Lysine decarboxylase in plants and its integration in quinolizidine alkaloid biosynthesis. Phytochemistry 22, 65-69. doi: 10.1016/S0031-9422(00)80 059-X

Shevyakova, N. I., Rakitin, V. Y., Duong, D. B., Sadomov, N. G., and Kuznetsov, V. V. (2001). Heat shock-induced cadaverine accumulation and translocation throughout the plant. Plant Sci. 161, 1125-1133. doi: 10.1016/S01689452(01)00515-5

Simon-Sarkadi, L., Ludidi, N., and Kocsy, G. (2014). Modification of cadaverine content by NO in salt-stressed maize. Plant Signal. Behav. 9:e27598. doi: $10.4161 /$ psb. 27598

Strohm, A. K., Vaughn, L. M., and Masson, P. H. (2015). Natural variation in the expression of ORGANIC CATION TRANSPORTER 1 affects root length responses to cadaverine in Arabidopsis. J. Exp. Bot. 66, 853-862. doi: $10.1093 /$ jxb/eru444

Sziderics, A. H., Oufir, M., Trognitz, F., Kopecky, D., Matušíková, I., Hausman, J.-F., et al. (2010). Organ-specific defence strategies of pepper (Capsicum annuum L.) during early phase of water deficit. Plant Cell Rep. 29, 295-305. doi: 10.1007/s00299-010-0822-z

Tokunaga, H., Kojima, M., Kuroha, T., Ishida, T., Sugimoto, K., Kiba, T., et al. (2011). Arabidopsis lonely guy (LOG) multiple mutants reveal a central role of the LOG-dependent pathway in cytokinin activation. Plant J. 69, 355-365. doi: 10.1111/j.1365-313X.2011.04795.x

Tomar, P. C., Lakra, N., and Mishra, S. (2013a). Cadaverine: a lysine catabolite involved in plant growth and development. Plant Signal Behav. 8:e25850. doi: $10.4161 /$ psb. 25850

Tomar, P. C., Lakra, N., and Mishra, S. N. (2013b). Effect of cadaverine on Brassica juncea (L.) under multiple stresses. Indian J. Exp. Biol. 51, 758-763.

Torrigiani, P., and Scoccianti, V. (1995). Regulation of cadaverine and putrescine levels in different organs of chick-pea seed and seedlings during germination. Physiol. Plant. 93, 512-518. doi: 10.1111/j.1399-3054.1995.tb0 6851.x

Torrigiani, P., Serafini-Fracassini, D., and Bagni, N. (1987). Polyamine biosynthesis and effect of dicyclohexylamine during the cell cycle of Helianthus tuberosus tuber. Plant Physiol. 84, 148-152.

Vaz, F. M., and Wanders, R. J. A. (2002). Carnitine biosynthesis in mammals. Biochem. J. 361, 417-429. doi: 10.1042/bj3 610417

Voigt, J., Deinert, B., and Bohley, P. (2000). Subcellular localization and light-dark control of ornithine decarboxylase in the unicellular green alga Chlamydomonas reinhardtii. Physiol. Plant. 108, 353-360. doi: 10.1034/j.1399-3054.2000.t01-1100403.x

Wink, M. (1992). "The role of quinolizidine alkaloids in plant-insect interactions," in Insect-Plant Interactions, ed. E. A. Bernays (Boca Raton, FL: CRC-Press), $133-169$.

Wink, M. (2010). "Molecular modes of action of cytotoxic alkaloids: from DNA intercalation, spindle poisoning, topoisomerase inhibition to apoptosis and multiple drug resistance," in The Alkaloids, Vol. 64, ed. G. A. Cordell (Amsterdam: Elsevier), 1-47. doi: 10.1016/S1099-4831(07)64001-2

Yamaguchi, K., Takahashi, Y., Berberich, T., Imai, A., Miyazaki, A., Takahashi, T., et al. (2006). The polyamine spermine protects against high salt stress in Arabidopsis thaliana. FEBS Lett. 580, 6783-6788. doi: 10.1016/j.febslet.2006.10.078

Yokota Hirai, M., Suzuki, H., Yamazaki, M., and Saito, K. (2000). Biochemical and partial molecular characterization of bitter and sweet forms of Lupinus angustifolius, an experimental model for study of molecular regulation of quinolizidine alkaloid biosynthesis. Chem. Pharm. Bull. 48, 1458-1461. doi: $10.1248 /$ cpb. 48.1458

Conflict of Interest Statement: The authors declare that the research was conducted in the absence of any commercial or financial relationships that could be construed as a potential conflict of interest.

Copyright (C) 2016 Jancewicz, Gibbs and Masson. This is an open-access article distributed under the terms of the Creative Commons Attribution License (CC BY). The use, distribution or reproduction in other forums is permitted, provided the original author(s) or licensor are credited and that the original publication in this journal is cited, in accordance with accepted academic practice. No use, distribution or reproduction is permitted which does not comply with these terms. 